University of Washington Tacoma

UW Tacoma Digital Commons

SIAS Faculty Publications

School of Interdisciplinary Arts and Sciences

$1-1-2016$

\title{
The Incidence of High Medical Expenses by Health Status in Seven Developed Countries
}

Katherine Elizabeth Baird

University of Washington Tacoma, kebaird@uw.edu

Follow this and additional works at: https://digitalcommons.tacoma.uw.edu/ias_pub

\section{Recommended Citation}

Baird, Katherine Elizabeth, "The Incidence of High Medical Expenses by Health Status in Seven Developed Countries" (2016). SIAS Faculty Publications. 633.

https://digitalcommons.tacoma.uw.edu/ias_pub/633

This Article is brought to you for free and open access by the School of Interdisciplinary Arts and Sciences at UW Tacoma Digital Commons. It has been accepted for inclusion in SIAS Faculty Publications by an authorized administrator of UW Tacoma Digital Commons. 


\title{
The Incidence of Large Medical Expenses by Health Status in Seven Developed Countries
}

\section{Katherine Baird}

Final Draft, Health Policy

Katherine Baird (2016). "The Incidence of Large Medical Expenses by Health Status in Seven Developed Countries," Health Policy, Vol 120(1), pp. 26-34.

\begin{abstract}
Health care policy seeks to ensure that citizens are protected from the financial risk associated with needing health care. Yet rising health care costs in many countries are leading to a greater reliance on out-of-pocket (OOP) measures. This paper uses 2010 household survey data from seven countries to measure and compare the burden OOP expenses place on individuals. It compares countries based on the extent to which citizens with health problems devote a large share of their income to OOP expenses. The paper finds that in all countries but France, and to a lesser extent Slovenia, citizens with health problems face considerably higher medical costs than do those without. As many as one-quarter of less healthy citizens in the US, Poland, Russia and Israel devote a large share of their income to OOP expenses. The paper also finds a strong crossnational correlation between the degree to which citizens face high OOP expenses, and the disparities in OOP expenses between those with and without health problems. The levels of high OOP spending uncovered, and their inequitable impact on those with health problems in the seven countries, underscore the potential for OOP measures to undermine core objectives of health care systems, including those of equitable financing, equal access, and improved health among the population.
\end{abstract}

KeyWords: Cost of illness; Health insurance; Health policy; Healthcare financing; Cost-sharing 


\section{Introduction}

The central purpose of health insurance is to pool the risk of high medical expenses so that these costs are instead spread across the population. Yet over the last decade, countries have responded to rising health care costs by introducing greater cost-sharing measures so that the users of health care face larger expenses [1-5]. This trend raises the question of how well the design of health insurance in different countries accomplishes the goal of protecting citizens from the risk of large out-of-pocket (OOP) expenses.

Certainly, relying on the users of health care to pay some (or occasionally even all) of their medical expenses can be good policy: It can help to reduce the risk of moral hazard associated with insurance by reducing the less valuable uses of health care dollars [6,7]. In many instances, paying out-of-pocket (OOP) can also be fairer than paying though insurance as some health expenses reflect individuals' preferences and income rather than medical necessity.

But high OOP requirements can also undermine the fundamental goals of a nation's health care system. They can render the financing of medical care less equitable, as paying for health care out-of-pocket is generally the most regressive way to finance it $[8,9]$. When they are high, OOP requirements can also cause some to meet their health care needs only by sacrificing other essential purchases, such as for food, shelter and education. Meeting these expenses also requires some to assume debt or liquidate assets intended for other purposes [10,11]. Not surprisingly, such ways of coping with high OOP requirements have been found to be more common among those in poor health and/or with chronic health problems [11,12].

Most importantly, paying for health care out-of-pocket can deter individuals from medical care, pharmaceutical products, and other needed medical goods [11, 13-19]. The poor $[14,19]$, elderly [19], and those with health problems $[11,20]$ have been shown to be the most 
sensitive to OOP requirements. Moreover, not only can cost-sharing practices lead to a reduction in the use of medical services and a weaker adherence to medication therapies, they have also been shown to result in poorer health outcomes $[13,19,21]$. For these reasons, researchers and policy makers are paying increased attention to the amount citizens pay out-of-pocket to receive medical services and products [1, 3-5, 22-25].

Yet very few studies investigate citizens' exposure to high OOP spending within a crossnational context. Making cross-country comparisons based on single country studies is generally difficult, as these comparisons are compromised by differences in the data sets, or in how out-ofpocket expenditures or income are defined and measured. However, cross-national comparisons are of increasing relevance, as countries face the similar public health challenges of reducing health care costs, distributing these costs fairly, and assuring equitable access to health care —all while meeting the growing medical needs of an aging population. How OOP expenditures feature into meeting or detracting from these goals is of growing concern in nearly all developed countries. Improved cross-national comparisons can aid in understanding the link between the scope and design of health insurance and the distribution of OOP expenditures. Such comparisons should also be included in comparative evaluations of how well countries meet their common health care objectives.

This paper contributes to a cross-national comparison of the burden created by out-ofpocket expenses by using nationally-representative household survey data from seven developed countries, where the data have been harmonized for the purpose of allowing cross-national comparisons. The paper matches groups of individuals across the seven countries based on their common responses to questions regarding their health, and compares these groups with respect to the percentage of household income spent on OOP expenditures. It then assesses the seven 
countries based on the frequency of high OOP expenses among those with similar health indicators, and the amount spent on OOP expenses at the tail end of the spending distribution (both defined below). The paper provides some of the best evidence to date on variation among countries in the degree to which those most in need of health care face large financial barriers to gaining access to it.

\section{Methods}

This paper measures the frequency with which citizens providing the same response to questions regarding their health (described below) in seven countries face high OOP expenses, where "high" is measured uniformly across the seven countries. It makes this comparison by calculating citizens' OOP medical spending relative to income in a single year, and then determining the percentage of individuals in each country with OOP expenses exceeding a threshold percentage of their income. It compares citizens across countries based on their common responses to one of three different measures of their health status, as detailed below. It also investigates differences within the seven countries in the share of income spent on OOP costs by those with health problems spending at the $90^{\text {th }}$ spending/income percentile of their cohort, thus comparing the impact of OOP requirements for those spending at the upper tail of each country's spending distribution.

For both of these estimations, the paper uses nationally-representative household survey data from seven developed countries made available through the Luxembourg Income Study (LIS). LIS produces harmonized versions of nations' household surveys to facilitate crossnational research on social policy. 
To choose the nations to compare in this study, we selected all LIS datasets that are no more than ten years old, that generate OOP spending levels roughly consistent with those published by the OECD, that employ standard definitions of OOP spending, and that have income levels close to those in Europe. This selection process left three countries in Europe (France, Poland, and Slovenia), three in Asia and the Middle East (Russia, Israel and Japan), and one in North America (the United States). For all seven countries except Japan (2008), the paper uses household survey data for the calendar year 2010. All data sets contain information on nationally-representative households, and provide weights for making national-level estimations. An online Appendix A provides information and notes on each data set used. Table 1 provides summary data for each country on household income and OOP expenses; as shown there, the number of observations in each country ranges from 3,900 in Slovenia to over 200,000 in the United States. All calculations presented here are based on weighted individual-level observations.

\section{Table 1 here}

As an indication of the representativeness of the countries chosen for this study, Table 2 compares a large number of developed countries based on two measures of their OOP spending reported by the OECD: the percentage of all health spending made up by OOP spending (column 1), and per-capita OOP expenditures (column 2). As shown, the countries in this study are somewhat representative of the range and distribution of OOP spending found in this larger sample of countries, both in terms of the relative (column 1) as well as absolute (column 2) size of OOP expenditures. Using relative indicators, France is at the low end of the distribution 
(OOP expenditures comprise $7.5 \%$ of all health expenditures), Israel is average (18.2\%), and Russia is at the high end (36.4\%). In absolute terms, France, Slovenia and Poland (around \$300 per capita) spend significantly below the average, Israel and Russia (around \$500) are fairly typical, and the US (\$988) is at the high end of the spending spectrum.

\section{Table 2 here}

Table 3 provides further detail on differences among the seven countries in this study. The first three columns present the relative importance in each nation of the three primary funding sources for the country's health care system: general tax revenue, social insurance payments, and private payments (the combination of private insurance and OOP expenses). As shown, France, Japan, Poland and Slovenia rely primarily on social insurance payments, whereas Russia and the US rely to a greater degree on private funding sources. Israel relies on a mixture of all three sources. Prior research has found that general taxes tends to result in the least regressive way to finance health care, while private financing tends to be the most [8]. Where available, the last column of Table 3 identifies the policies used in countries to limit OOP expenses. As shown, the mix of policies is typical of what is found in other countries: special protection is offered to certain populations (typically the ill, children elderly, and/or the poor), and in some instances, countries have established income-based limits on OOP expenditures.

\section{Table 3 here}


Out-of-pocket Spending. Out-of-pocket spending is defined by LIS as total household expenditures on medical products, appliances and equipment, outpatient services and hospital services, and excludes health insurance premiums. The countries in this study adhere relatively closely to this definition, which comes from Code 06 of the United Nation's Classification of Individual Consumption According to Purpose. To verify the quality of LIS's OOP spending data, we compare OOP spending in each of the seven surveys with amounts published by the OECD (compare Table 1 with Table 2). All seven country estimates from LIS fall within $72 \%$ to 96\% of the OECD's estimates. That per-capita OOP estimates from LIS are below the OECD's is expected: household surveys generally exclude the institutionalized population (e.g., those in long-term care facilities) and individuals who died earlier in the year. For both of these populations, OOP spending can be high. Recent evidence also raises questions about the reliability of the OECD's estimates [26].

High Medical Expenses. This paper follows the common practice of labeling households as having high OOP spending when the amount they spend exceeds a certain percentage of income $[1,5,9,22,27]$. Especially in developed countries, income is the most commonly used measure of a household's ability to pay. In this paper all members of a household are designated as having high OOP spending when the amount spent exceeds $10 \%$ of their income, or $5 \%$ if the household is in poverty, both of which are defined below. This measurement reflects the most common practice of using a $10 \%$ threshold, but often lowering it if the household is poor $[1,28,29]$. It should be noted, however, that this measure of "high spending" is conservative insofar as it entails an arbitrary division between the "poor" and the "non-poor." It also does not capture as high-spenders those with low costs due to their underutilization of medical care or medication, which could be significant [30]. 
Income. LIS data provide excellent information on household income which is consistently measured across different countries. The paper defines income as disposable income, which is superior to other measures since it takes into account the value of government taxes paid and social transfers received. This is especially important for those with health problems, since disposable income includes any benefits received from disability, social insurance, social assistance, and public pension policies. As with OOP spending, income is measured at the household level.

Poverty. Individuals are identified as in poverty when the equivalized form of household disposable income (disposable income divided by the square root of household size) is below a poverty threshold. For this threshold, this paper employs the European Commission's definition of poverty, which is income below $60 \%$ of the median. Those individuals with (equivalized) disposable income below $60 \%$ of the nation's equivalized median value are thus labeled as being poor. Because all individuals in the same household have the same equivalized income, they all have the same poverty status.

Health Status. The seven household surveys each capture respondent's and their family members' health status through responses to one or two of three different health-related questions. The answers to two of these three questions are coded as 1 if the individual answers "yes" to the specific health problem, and 0 otherwise. For one such question, a "yes" response indicates the individual has a permanent health condition (either physical or mental) that limits basic activity; all countries except for Japan and France provide information for this "Disability" question. The percent of yes (disabled) responses differs across countries, ranging from $1 \%$ in Slovenia to $10 \%$ in the US (see online Appendix B). Much of this variation likely reflects the 
specific way the Disability question is worded in the different countries (see online Appendix A for detail).

A second health indicator question asks if a household member has a chronic illness or disease. France and Japan were the only countries to provide responses to this "Illness" question (in France's case, it captures whether or not an individual was hospitalized during the previous year, see Online Appendix A), with Japan providing it for the household head and spouse only (see online Appendix A). Japan's “Illness" rate (25\%) is slightly higher than France's (21\%), although as noted, the question was asked differently in the two countries.

Japan, Russia, Slovenia and the United States all provide information on a third measure of individuals' health: respondents ranked each individual household member's health from 1 (excellent) to 5 (bad). For the purposes of this study, this variable is used to create a third health indicator variable, where individuals are deemed in "Poor Health" if they report either being in poor or bad health (a ranking of 4 or 5), or they are deemed not in poor health (i.e., they report a health ranking of 1,2 or 3). In Slovenia, this variable is available only for household heads, and in Japan it is only provided for household heads and spouses. The percentage of the population reporting to be in poor health ranges from $12 \%$ to $14 \%$, suggesting a great deal of similarity across countries in how respondents categorize household members' health. For this reason, the Poor Health indicator is likely the most reliable of the three used in this study for matching individuals across the seven countries based on their health. .Detail on the distribution of the population in each country by health status can be found in an online Appendix B.

\section{Results}


How does the degree of financial protection against the risk of large OOP expenses compare across the seven countries? How does this protection differ for those with health problems compared with the rest of the population? Finally, how much do those with health problems pay in high OOP expenses at the tail end of the spending distribution in the different countries?

To answer the first question, Table 4 column 1 presents country-level estimates of the percentage of citizens with high OOP expenses in each of the seven countries, where "high" is as defined earlier. As shown, more than $10 \%$ of individuals in the US, Poland, Israel and Russia lived in households with high OOP spending, and only in France did less than 5\% of individuals have high OOP expenses.

\section{Table 4 here}

To compare the incidence of high OOP spending by citizens' health status in the seven countries, Table 4 presents estimates of the percentage of individuals with large OOP expenses by health status based on each of the three different indicators of health problems previously discussed ("Disability", "Illness", and "Poor Health"). Table 4 also presents the amount of OOP expenses as a share of income by health status, for those spending at the $90^{\text {th }}$ percentile. For instance, among citizens reporting to be disabled, those in Slovenia spending at the $90^{\text {th }}$ percentile spent $9 \%$ of their income on OOP expenses, whereas the same group at the same point of the spending distribution in Israel spent $18 \%$ of their income on OOP expenses. Together these two statistics provide comparative indicators of the extent to which health care costs within 
a county fall disproportionately on those who need it more: the first measures the prevalence of high OOP costs, and the second measures how high these costs can reach.

As Table 3 shows, differences in the incidence of high OOP spending between the disabled and non-disabled population exceeds ten percentage points in the United States, Poland, Israel and Russia, while differences in Slovenia (four percentage points) are the smallest. Comparing rates between those with and without a chronic illness in France and Japan reveals small difference in the prevalence of high OOP expenses between these two groups, perhaps reflecting the weaker nature of this indicator of individuals' health status.

The last two columns in Table 4 present rates of high OOP spending among those categorized in poor health versus not in poor health. By this indicator, we see that those in poor health in Japan, Russia and the US are at significantly higher risks of large OOP expenses compared with those not in poor health. The gap between the two populations is largest in Russia, where an estimated $33 \%$ of those in poor health had high OOP expenses in 2010, compared with $14 \%$ among those not in poor health. By this Poor Health indicator, Slovenia offers the best financial protection of the four countries, as only $15 \%$ of Slovenians reporting poor health had high OOP expenses, and only $9 \%$ of Slovenians not in poor health had high expenses.

With the exception of the Illness variable — which is very likely a weak indicator of health status (see online Appendix A)--the results reveal that those with health problems are exposed to a significantly higher risk of large OOP spending than are those without them: in all countries, the risk roughly doubles for this population compared with those without health problems. But in France especially, and to a lesser extent Slovenia, "greater risk" is relative to a population provided significant protection from high financial costs. In absolute terms, the 
overall estimates show that a quarter or more of citizens with health problems in Poland, Russia, the US and Israel had high OOP expenses in 2010, with slightly better outcomes in Japan.

Comparing spending levels at the $90^{\text {th }}$ percentile for each group in the seven countries similarly reveals large difference between them: typically those with health problems spend about 75 percent more than do those without health problems. For instance, a disabled person at the 90 percentile of spending among the disabled in Poland devoted $16 \%$ of her income to OOP expenses, whereas a non-disabled at this point of the non-disabled spending distribution in Poland spent only $9 \%$ of income on OOP expenses.

Figure 1 graphically represents the cross-country relationship between the frequency of high OOP expenses in each country (the $\mathrm{X}$ axis) and the difference in this frequency between those with and without indicators of a health problem (Y axis). For instance, as shown in Table 4 column 1, an estimated $15 \%$ of the population in Israel faces high OOP costs (X axis), whereas there is an estimated 11 percentage point difference is high costs ( $\mathrm{Y}$ axis) between those who are disabled and those who are not (26\% versus $15 \%)$. This shows a clear pattern where countries in which large OOP expenses are more common ( $\mathrm{X}$ axis) also have a larger gap between the frequency of high OOP spending between citizens with and without health problems. In other words, where a country's health policies expose citizens to a higher overall risk of large OOP expenses, this translates into a greater disparity between those with and without health problems in the financial burden health care places on them. This association makes intuitive sense: if health policy within a country exposes a larger percentage of citizens to substantial costs from using medical services, then we would expect that additional exposure to fall disproportionately on those who most need health care and medical products. 


\section{Figure 1 here}

The sample of counties in this study, then, reveals a strong pattern where exposure to a higher risk of incurring large OOP expenses places a more uneven financial burden on those with health problems versus those without. But not only do we see this association, but we also see that a higher exposure to large OOP expenses is associated with more extreme levels of OOP requirements at the household level. This is shown in Figure 2, where the $\mathrm{X}$ axis once again measures the incidence of high OOP spending in each country, but the Y axis now captures the amount spent on OOP expenses as a share of income at the $90^{\text {th }}$ percentile of spending among those with indicators of health problems (see Table 4). As Figure 2 shows, nations that expose citizens to a higher risk of large OOP expenses ( $\mathrm{X}$ axis), also expose their citizens with health problems to especially high levels of spending requirements. For instance in Russia (the northeast corner of Figure 2), 17\% of its population had high OOP expenses in 2010, and among those reporting to be disabled, the $90^{\text {th }}$ percentile of OOP/income spending reached $20 \%$. The distinct pattern depicted in Figure 2 suggests a separate manifestation of the problem associated with high exposure to OOP expenses: it tends to also expose citizens in poor health to extremely large levels of out-of-pocket medical expenses.

\section{Figure 2 here}

In our sample of countries, then, the degree of exposure to large OOP expenses is closely associated with the extent to which those with health problems disproportionately face high OOP expenses, and the chance that these costs will reach extremely high levels. This association 
becomes even more concerning when one examines who it is that tends to have health problems. Table 5 displays the age and income profile of those reporting health problems in the seven countries. On average, those with indicators of health problems were about twice as likely to be poor, and several times more likely to be 65 years or older. As shown elsewhere, the risk of having large OOP expenses is especially pronounced among the poor and elderly, where it is not uncommon for one-quarter or more of poor citizens to devote at least $5 \%$ of their income to outof-pocket expenses [31]. Thus, in the sample countries here, exposure to high OOP expenses disproportionately shifts health care financing to those with health problems, thereby placing a greater financial burden on the poor and elderly-- the precise citizens least able to bear these expenses, and the ones most likely to respond to them by reducing their health care consumption $[11,14,19,20]$.

\section{Table 5 here}

\section{Discussion}

This study presents comparable cross-national indicators of the incidence of high out-ofpocket medical expenses among those with similar indicators of their health status. Within each of the seven countries, the design and scope of insurance leaves the unhealthy more exposed to high OOP costs than it does the healthy. Looking across countries, the absolute magnitude of this risk varies considerably. Health policy in France provides the best financial protection against the costs associated with adverse health outcomes, with Slovenia a distant second. Numerous measures in France help account for citizens' minimal exposure to high OOP expenses. For one, most French citizens purchase secondary private insurance to cover the at 
times extensive cost-sharing requirements of public insurance. And those below a particular income threshold are provided supplemental public insurance at no cost. Many vulnerable citizens (including those with particular health problems) are also exempt from all OOP requirements [32]. These measures explain why overall, OOP expenditures account for only $7.5 \%$ of France's health care expenditures. Indeed, the results here show a .78 correlation between a country's reliance on OOP expenditures (column 1 of Table 2) and the percent of citizens with high OOP expenses (Column 1 Table 4), and a stronger .83 correlation between a reliance on OOP and the amount spent by those at the $90^{\text {th }}$ spending percentile (Column 1 Table 4).

By contrast, the US, Poland, Russia and Israel stand out for the significant exposure their citizens have to high OOP expenses, an outcome that the paper shows in these countries disproportionately shifts the financing of health care costs to low-income households, citizens in poor health, and the elderly. Moreover, it also is associated with these individuals being more exposed to the risk of extremely high OOP expenses. Overall in our sample, nations relying on private spending sources do tend to place a more inequitable financial burden on those with health problems; however, this association is also almost completely attributable to the OOP component of private expenditures rather than a reliance on private insurance.

There are a couple of important limitations to this study. First, it estimates the risk of high OOP spending by actual spending patterns. As such it does not count those for whom OOP spending falls below the threshold of "high" only because they forgo needed medical services and products rather than pay its cost. This omission may lead to significantly underestimating the risk of incurring high medically-related costs [30], especially in countries with high levels of OOP requirements [33]. Second, the comparisons are based on self-reported measures of health, 
and the definitions of "Illness" and "Disability" used in each of the countries often differed. For this reason, the comparisons across countries for these variables should be considered suggestive rather than exact, and likely underestimate true disparities within countries. Third, no single measure of citizens' health status is available for all seven countries.

Finally, in measuring the frequency and magnitude of large OOP spending, the paper does not address what the right amount or the appropriate conditions are for individuals to pay out-of-pocket, as opposed to pre-paying collectively via taxes or premiums. Paying out-ofpocket may advance the objective of constraining the burden medical care places on public budgets and private premiums, and moderating citizens' incentive to overconsume health care [6,7]. It may also reflect a preferred reduction in the cost of premiums in exchange for higher OOP expenses. Yet the levels of high OOP spending uncovered in most of the countries here, and their disparate effect on individuals with health problems, the poor and the elderly, underscores its widespread potential to undermine core objectives of health care systems, including those of equitable financing, equal access, and improved health among the population.

\section{Conclusions}

Despite universal insurance in six of the seven countries in this study, and the widespread existence of policies that supposedly limit citizens' financial exposure to high OOP expenses $[4$, 34, 35, see Table 3], the paper finds that large levels of OOP spending are common in all but France. It is perhaps noteworthy that according to one attempt to classify nations' health care systems, France, Poland, Japan and Israel all have common institutional arrangements for regulating, financing, and providing health care within their nation [36]. Yet according to this paper's findings, these similarities do not translate into similar levels of financial protection. 
Exactly how countries do and do not accomplish the level of financial protection each provides deserves further detailed analyses, although as previously discussed, health policy in France is specifically designed to restrict the potential for OOP expenses at the household level to climb. Indeed, the findings here indicate the centrality of this feature of health care policy to achieve equitable financing of and equal access to health care.

In addition to more closely investigating how and why OOP expenses in countries can mount (or not), another implication of this study is the increasing importance of monitoring the incidence of high OOP spending within countries. That it is a common occurrence in many countries reveals an aspect of nations' health care system that is currently not very visible. Collecting and publicizing this data is especially important given that health care costs are rising, as have out-of-pocket costs in most countries.

A challenge for public health is making sure that OOP requirements are consistent with the goals of financing equity, equal access, and improved medical outcomes. For countries to attain financial protection on par with that achieved in France, they will need to enact more comprehensive income-based limits on OOP spending than currently exist in most countries. However, the magnitude of financial risk revealed here indicates that in order to reduce health care costs, countries should seek alternative methods to the one examined here: shifting the cost to those who need health care. 


\section{References}

[1] Collins SR, Rasmussen PW, Doty MM, Beutel S. Too high a price: out-of-pocket health care costs in the United States. The Commonwealth Fund, November 2014.

[2] OECD. Health at a Glance: OECD Indicators. Paris: OECD Publishing, 2013.

[3] Tambor M, Pavolova M, Woch P, Groot W. Diversity and dynamics of patient cost sharing for physicians' and hospital services in the 27 European Union countries. European Journal of Public Health 2010; 21: 585-590.

[4] Zare H, Anderson G. Trends in cost sharing among select high income countries 2000-2010. Health Policy 2013; 112: 35-44.

[5] Luczak J, García Gómez P. Financial burden of drug expenditures in Poland. Health Policy 2012; 105: 256-264.

[6] Baiker K, Goldman D. Patient cost-sharing and healthcare spending growth. Journal of Economic Perspectives 2011; 25(2): 47-68.

[7] Swartz K. Cost-sharing: effects on spending and outcomes. The Synthesis Project, Issue 20. Princeton, New Jersey: Robert Wood Johnson Foundation. 2010

[8] Wagstaff A, van Doorslaer E, van der Burg H, et al. Equity in the finance of health care: Some further international comparisons. Journal of Health Economics 1999; 18: 263-290.

[9] Waters HR, Anderson GF, Mays J. Measuring financial protection in health in the United States. Health Policy 2004; 69: 339-349.

[10] Atanasova F, Pavlova M, Moutafova E, Rechel B, Groot W. Out-of-pocket payments for health care services in Bulgaria: Financial burden and barrier to access. European Journal of Public Health 2012; 23: 916-922. 
[11] Tambor M, Pavlova M, Rechel B, Golinowska S, Sowada C, Groot W. The inability to pay for health services in Central and Eastern Europe. European Journal of Public Health 2014; 24 : 378-385.

[12] Hwang W, Weller W, Ireys H, Anderson G. Out-of-pocket medical spending for care of chronic conditions. Health Affairs 2001; 6: 267-78.

[13] Eaddy MT, Cook CL, O’Day K, Burch KP, Cantrell CR. How patient cost-sharing trends affect adherence and outcomes. P T 2012; 37: 45-55.

[14] Chernew, M, Gibson TB, Yu-Isenberg K, Sokol, MC, Rosen AB, Fendrick AM. Effects of increased patient cost sharing on socioeconomic disparities in health care. Journal of General Internal Medicine 2008; 23(8): 1131-6.

[15] Lesen E, Sundell KA, Carlsten A, Mardby AC, Jonsson AK. Is the level of patient copayment for medicines associated with refill adherence in Sweden? European Journal of Public Health 2013; 24(1): 85-90.

[16] Rector TS,Venus PJ. Do drug benefits help Medicare beneficiaries afford prescribed drugs? Health Affairs 2004; 23(4): 213-222.

[17] Schoen C, Osborn R, Squires D, Doty M, Pierson R, Applebaum S. How health insurance design affects access to care and costs, by income, in eleven countries. Health Affairs 2010; 29: 2323-2334.

[18] Starner CI, Alexander GC, Brown K, Qiu Y, Wickersham, PJ, Gleason PP. Specialty drug coupons lower out-of-pocket costs and may improve adherence at the risk of increasing premiums. Health Affairs 2014; 33: 1761-9. 
[19] Tamblyn R, Laprise R, Hanley JA, et al. Adverse events associated with prescription drug cost sharing among poor and elderly persons. Journal of the American Medical Association 2001; 285: 421-429.

[20] Lee JC, Hasnain-Wynia R, Lau DT. Delay in seeing a doctor due to cost. Health Services Research 2012; 47: 698-720.

[21] Soumerai SB, Ross-Degnan D, Avorn J, McLaughlin TJ, Choodnovskiy I. Effect of Medicaid drug-payment limits on admission to hospitals and nursing homes. New England Journal of Medicine 1991; 325: 1072-7.

[22] Law, MR, Daw JR, Cheng L, Morgan SG. Growth in private payments for health care by Canadian households. Health Policy 2013; 110: 141-146.

[23] Kronenberg C, Barros PP. Catastrophic health care expenditures-drivers and protection: The Portuguese case. Health Policy 2014; 115: 44-51.

[24] Balabanova D, Roberts B, Richardson E, Haerpfer C, McKee M. Health care reform in the former Soviet Union: Beyond the transition. Health Services Research 2012; 47(2): 840-64. [25] OECD. Out-of-pocket Expenditure on Health Per Capita, in Health: Key Tables from OECD, No. 6. Paris: OECD; 2014. Available from: http://dx.doi.org/10.1787/oopexphtlcatable-2014-1-en.

[26] Calcoen P, Moens D, Verlinden P, van de Ven WPMM, Pocolet J. Improved estimates of Belgian private health expenditure can give important lessons to other OECD countries. Health Policy 2015; 119: 341-355.

[27] Ziller EC, Coburn A, Yousefina AE. OOP health spending and the rural underinsured. Health Affairs 2006; 25: 1688-1699. 
[28] Cunningham PJ. Chronic Burdens: the persistently high OOP health care expenses faced by many Americans with chronic conditions. Commonwealth Fund Issue Brief 2009; 63. [29] Schoen C, Hayes SL, Collins SR, Lippa JA, Radley DC. America's underinsured. New York: Commonwealth Fund, 2014.

[30] Abraham JM, DeLeir T, Royalty AB. Moral hazard matters: measuring relative rates of underinsurance using threshold measures. Health Services Research 2010; 45(3): 806-824. [31] Baird K. High out-of-pocket medical spending among the poor and elderly in nine developed countries. Health Services Research 2015; forthcoming. [32] Kaiser Family Foundation. Cost sharing for health care: France, Germany, and Switzerland. Menlo Park, CA: Kaiser Family Foundation. 2009. Available from https://kaiserfamilyfoundation.files.wordpress.com/2013/01/7852.pdf.

[33] Karaca-Mandic, P, Joyce GF, Goldman DP, Laouri M. Cost sharing, family health care burden, and the use of specialty drugs for rheumatoid arthritis. Health Services Research 2010; 45(5 Pt 1): 1227-1250.

[34] Paris VM, Devaux M, Wei L. Health systems institutional characteristics: A survey of 29 OECD countries. Paris: OECD, 2010. Available from: http://dx.doi.org/10.1787/5kmfxfq9qbnr-en.

[35] Commonwealth Fund. International profiles of health care systems. New York: Commonwealth Fund, 2013. Available from: http://www.commonwealthfund.org/ /media/Files/Publications/Fund\%20Report/2013/Nov/1717 _Thomson_intl_profiles_hlt_care_sys_2013_v2.pdf 
[36] Böhm K, Schmid A; Götze R, Landwehr C, Rothgang H. Classifying OECD healthcare systems: A deductive approach. TranState Working Papers, No. 165, 2012. Available from: http://hdl.handle.net/10419/64809 
Table 1: Household Income and Out of Pocket Expenses, by Country (US PPP\$)

\begin{tabular}{ccccc} 
HH Disposable Income & \multicolumn{3}{c}{ Out of Pocket Expenses } \\
\cline { 4 - 6 } Median & Per & Average & Median \\
Average & Equivalized & Capita & HH & HH \\
\cline { 4 - 6 } & & & &
\end{tabular}

\begin{tabular}{rccccc} 
No. Obs (1) & Average & Equivalized & Capita & HH & HH \\
\hline 40,837 & $\$ 44,513$ & $\$ 23,510$ & $\$ 235$ & $\$ 602$ & $\$ 282$ \\
20,203 & $\$ 39,350$ & $\$ 16,192$ & $\$ 372$ & $\$ 1,275$ & $\$ 508$ \\
$5,318 / 5,332$ & $\$ 51,727$ & $\$ 22,824$ & $\$ 419$ & $\$ 1,537$ & $\$ 744$ \\
107,147 & $\$ 23,914$ & $\$ 10,932$ & $\$ 285$ & $\$ 821$ & $\$ 464$ \\
$15,027 / 15,037$ & $\$ 24,220$ & $\$ 10,490$ & $\$ 387$ & $\$ 1,130$ & $\$ 359$ \\
$11,514 / 3,924$ & $\$ 34,906$ & $\$ 18,452$ & $\$ 255$ & $\$ 685$ & $\$ 0$ \\
$155,807 /$ & & & & & \\
203,799 & $\$ 63,837$ & $\$ 29,990$ & $\$ 708$ & $\$ 2,024$ & $\$ 850$
\end{tabular}

(1) Where there are two numbers, the first is for observations with the Disabled variable, and the second is for observations using the Health Status variable. See online Appendix A for more detail on observations.Calculations are based on the number of observations indicated.

Notes: HH=Household. All amounts expressed in 2010 US\$ (except Japan, 2008) using the OECD's Purchasing Power Parity index for private consumption, available at http://stats.oecd.org/Index.aspx?datasetcode=SNA_TABLE4\#

Source: Authors calculation based on LIS data (www.lisdatacenter.org). 
Table 2: Out-of-Pocket Medical Expenses, Per Capita and as a Share of Total Health Expenditures, by Country

\begin{tabular}{rrc} 
& & $\begin{array}{c}\text { Per Capita } \\
\text { OOP }\end{array}$ \\
\cline { 2 - 3 } & $\begin{array}{r}\text { OOP } \% \\
\text { Health }\end{array}$ & US $\$$ PP) \\
\cline { 2 - 3 } USA & & \\
France & $\mathbf{1 2 . 0}$ & $\mathbf{\$ 9 8 8}$ \\
Israel & $\mathbf{7 . 5}$ & $\mathbf{\$ 3 0 0}$ \\
Japan & $\mathbf{1 8 . 2}$ & $\mathbf{\$ 5 0 1}$ \\
Poland & $\mathbf{1 4 . 4}$ & $\mathbf{\$ 4 3 6}$ \\
Slovenia & $\mathbf{2 2 . 1}$ & $\mathbf{\$ 3 1 7}$ \\
Russia & $\mathbf{1 2 . 2}$ & $\mathbf{\$ 3 0 0}$ \\
Switzerland & $\mathbf{3 6 . 4}$ & $\mathbf{\$ 4 7 2}$ \\
Australia & 25.1 & $\$ 1,253$ \\
Belgium & 19.3 & $\$ 730$ \\
Canada & 20.8 & $\$ 836$ \\
Czech Rep & 14.4 & $\$ 637$ \\
Denmark & 14.9 & $\$ 286$ \\
Estonia & 13.2 & $\$ 598$ \\
Finland & 18.6 & $\$ 242$ \\
Germany & 19.6 & $\$ 645$ \\
Hungary & 13.1 & $\$ 581$ \\
Iceland & 26.3 & $\$ 447$ \\
Ireland & 18.2 & $\$ 619$ \\
Italy & 18.2 & $\$ 690$ \\
Korea & 17.5 & $\$ 553$ \\
Luxembourg & 34.0 & $\$ 704$ \\
New Zealand & 9.6 & $\$ 448$ \\
Portugal & 10.5 & $\$ 318$ \\
Slovak Rep & 25.8 & $\$ 721$ \\
Spain & 21.7 & $\$ 442$ \\
Sweden & 19.8 & $\$ 597$ \\
UK & 16.3 & $\$ 613$ \\
OECD AVG & $\mathbf{1 9 . 0}$ & \\
\hline OE & &
\end{tabular}

Source: OECD Health Statistics 2014, available at http://stats.oecd.org/Index.aspx?DataSetCode=SHA. Per-capita expressed in 2010 purchasing power parity dollars (PPP\$), except Switzerland (2004), and Japan (2008). 
Table 3: Source of Health Care Financing and Limits on OOP, by Country (2010)

\begin{tabular}{|ll|}
\hline \multicolumn{2}{|c|}{ Financing of Health Care (\% of total) } \\
\hline \multicolumn{3}{|c|}{ Public } & Private \\
General & Soc. Insurance
\end{tabular}

\begin{tabular}{|c|c|c|c|c|}
\hline & General & Soc. Insurance & & Limits on OOP \\
\hline France & 2.8 & 74.2 & 22.0 & $\begin{array}{l}\text { Caps on } \\
\text { deductibles, some } \\
\text { exemptions for low } \\
\text { income, ill, disabled } \\
\text { and chldren }\end{array}$ \\
\hline Israel & 17.0 & 46.5 & 35.3 & N/A \\
\hline Japan & 9.4 & 72.0 & 18.1 & $\begin{array}{l}\text { Coinsurance } \\
\text { reduced after } \\
\text { monthly cap } \\
\text { reached. Reduced } \\
\text { cost sharing for low } \\
\text { income, children, } \\
\text { young children, and } \\
\text { elderly. }\end{array}$ \\
\hline Poland & 5.9 & 65.8 & 28.3 & $\begin{array}{l}\text { Cost sharing } \\
\text { exemptions for } \\
\text { certain medical } \\
\text { condititions }\end{array}$ \\
\hline Russia & 29.5 & 23.8 & 46.7 & N/A \\
\hline Slovenia & 4.4 & 68.9 & 26.7 & N/A \\
\hline US & 24.6 & 23.8 & 51.6 & $\begin{array}{l}\text { Little cost sharing } \\
\text { for low income } \\
\text { individuals on } \\
\text { Medicaid }\end{array}$ \\
\hline
\end{tabular}

Sources: OECD Health at a Glance 2012; Paris et al. 2010; Commonwealth Fund 2013. 
Table 4: Out of Pocket (OOP) Expenses for Total Population and By Health Status:

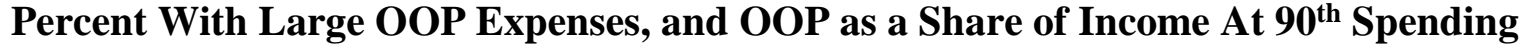
Percentile

\begin{tabular}{|c|c|c|c|c|c|c|c|}
\hline & \multirow{2}{*}{$\begin{array}{c}\text { Total } \\
\text { Population } \\
\end{array}$} & \multicolumn{2}{|c|}{ Disabled } & \multicolumn{2}{|c|}{ Illness } & \multicolumn{2}{|c|}{ Poor Health } \\
\hline & & Yes & No & Yes & No & Yes & No \\
\hline \multicolumn{8}{|l|}{ France } \\
\hline \% High OOP & $3 \%$ & $\mathrm{n} / \mathrm{a}$ & $\mathrm{n} / \mathrm{a}$ & $4 \%$ & $3 \%$ & $\mathrm{n} / \mathrm{a}$ & $\mathrm{n} / \mathrm{a}$ \\
\hline 90th \% OOP/Inc & $4 \%$ & $\mathrm{n} / \mathrm{a}$ & $\mathrm{n} / \mathrm{a}$ & $5 \%$ & $3 \%$ & $\mathrm{n} / \mathrm{a}$ & $\mathrm{n} / \mathrm{a}$ \\
\hline \multicolumn{8}{|l|}{ Israel } \\
\hline \% High OOP & $15 \%$ & $26 \%$ & $15 \%$ & $\mathrm{n} / \mathrm{a}$ & $\mathrm{n} / \mathrm{a}$ & $\mathrm{n} / \mathrm{a}$ & $\mathrm{n} / \mathrm{a}$ \\
\hline 90th \% OOP/Inc & $11 \%$ & $18 \%$ & $10 \%$ & $\mathrm{n} / \mathrm{a}$ & $\mathrm{n} / \mathrm{a}$ & $\mathrm{n} / \mathrm{a}$ & $\mathrm{n} / \mathrm{a}$ \\
\hline \multicolumn{8}{|l|}{ Japan } \\
\hline$\%$ High OOP & $9 \%$ & $\mathrm{n} / \mathrm{a}$ & $\mathrm{n} / \mathrm{a}$ & $13 \%$ & $9 \%$ & $21 \%$ & $8 \%$ \\
\hline 90th \% OOP/Inc & $7 \%$ & $\mathrm{n} / \mathrm{a}$ & $\mathrm{n} / \mathrm{a}$ & $9 \%$ & $7 \%$ & $15 \%$ & $7 \%$ \\
\hline \multicolumn{8}{|l|}{ Poland } \\
\hline \% High OOP & $13 \%$ & $25 \%$ & $11 \%$ & $\mathrm{n} / \mathrm{a}$ & $\mathrm{n} / \mathrm{a}$ & $\mathrm{n} / \mathrm{a}$ & $\mathrm{n} / \mathrm{a}$ \\
\hline 90th \% OOP/Inc & $10 \%$ & $16 \%$ & $9 \%$ & $\mathrm{n} / \mathrm{a}$ & $\mathrm{n} / \mathrm{a}$ & $\mathrm{n} / \mathrm{a}$ & $\mathrm{n} / \mathrm{a}$ \\
\hline \multicolumn{8}{|l|}{ Russia } \\
\hline \% High OOP & $17 \%$ & $29 \%$ & $15 \%$ & $\mathrm{n} / \mathrm{a}$ & $\mathrm{n} / \mathrm{a}$ & $33 \%$ & $14 \%$ \\
\hline 90th \% OOP/Inc & $12 \%$ & $20 \%$ & $12 \%$ & $\mathrm{n} / \mathrm{a}$ & $\mathrm{n} / \mathrm{a}$ & $21 \%$ & $11 \%$ \\
\hline \multicolumn{8}{|l|}{ Slovenia } \\
\hline \% High OOP & $7 \%$ & $11 \%$ & $7 \%$ & $\mathrm{n} / \mathrm{a}$ & $\mathrm{n} / \mathrm{a}$ & $15 \%$ & $9 \%$ \\
\hline 90th \% OOP/Inc & $7 \%$ & $9 \%$ & $7 \%$ & $\mathrm{n} / \mathrm{a}$ & $\mathrm{n} / \mathrm{a}$ & $11 \%$ & $7 \%$ \\
\hline \multicolumn{8}{|l|}{ United States } \\
\hline$\%$ High OOP & $13 \%$ & $25 \%$ & $11 \%$ & $\mathrm{n} / \mathrm{a}$ & $\mathrm{n} / \mathrm{a}$ & $25 \%$ & $10 \%$ \\
\hline 90th \% OOP/Inc & $9 \%$ & $17 \%$ & $9 \%$ & $\mathrm{n} / \mathrm{a}$ & $\mathrm{n} / \mathrm{a}$ & $17 \%$ & $8 \%$ \\
\hline
\end{tabular}

Note: Total population based on entire dataset. All estimations based on weighted observations for calendar year 2010, except Japan (2008). High OOP defined as OOP expenditures exceeding $10 \%$ of disposable income, or 5\% of household income is below $60 \%$ of the median.

Source: Authors calculations based on LIS data (www.lisdatacenter.org). 
Table 5: Composition of Subpopulations Based on Health Status: Percent that are Poor and Elderly

\begin{tabular}{|c|c|c|c|c|c|c|c|c|c|c|c|c|}
\hline & \multicolumn{6}{|c|}{----------Percent in Poverty by Health Status------ } & \multicolumn{6}{|c|}{-------Percent Elderly by Health Status------- } \\
\hline & \multicolumn{2}{|c|}{ Disabled } & \multicolumn{2}{|c|}{ Illness } & \multicolumn{2}{|c|}{ Poor Health } & \multicolumn{2}{|c|}{ Disabled } & \multicolumn{2}{|c|}{ Illness } & \multicolumn{2}{|c|}{ Poor Health } \\
\hline & Yes & No & Yes & No & Yes & No & Yes & No & Yes & No & Yes & No \\
\hline France & $\mathrm{n} / \mathrm{a}$ & $\mathrm{n} / \mathrm{a}$ & $13 \%$ & $16 \%$ & $\mathrm{n} / \mathrm{a}$ & $\mathrm{n} / \mathrm{a}$ & $\mathrm{n} / \mathrm{a}$ & $\mathrm{n} / \mathrm{a}$ & $18 \%$ & $16 \%$ & $\mathrm{n} / \mathrm{a}$ & $\mathrm{n} / \mathrm{a}$ \\
\hline Israel & $28 \%$ & $28 \%$ & $\mathrm{n} / \mathrm{a}$ & $\mathrm{n} / \mathrm{a}$ & $\mathrm{n} / \mathrm{a}$ & $\mathrm{n} / \mathrm{a}$ & $10 \%$ & $10 \%$ & $\mathrm{n} / \mathrm{a}$ & $\mathrm{n} / \mathrm{a}$ & $\mathrm{n} / \mathrm{a}$ & $\mathrm{n} / \mathrm{a}$ \\
\hline Japan & $\mathrm{n} / \mathrm{a}$ & $\mathrm{n} / \mathrm{a}$ & $19 \%$ & $16 \%$ & $25 \%$ & $16 \%$ & $\mathrm{n} / \mathrm{a}$ & $\mathrm{n} / \mathrm{a}$ & $20 \%$ & $23 \%$ & $41 \%$ & $20 \%$ \\
\hline Poland & $22 \%$ & $15 \%$ & $\mathrm{n} / \mathrm{a}$ & $\mathrm{n} / \mathrm{a}$ & $\mathrm{n} / \mathrm{a}$ & $\mathrm{n} / \mathrm{a}$ & $29 \%$ & $11 \%$ & $\mathrm{n} / \mathrm{a}$ & $\mathrm{n} / \mathrm{a}$ & $\mathrm{n} / \mathrm{a}$ & $\mathrm{n} / \mathrm{a}$ \\
\hline Russia & $16 \%$ & $21 \%$ & $\mathrm{n} / \mathrm{a}$ & $\mathrm{n} / \mathrm{a}$ & $22 \%$ & $21 \%$ & $51 \%$ & $8 \%$ & $\mathrm{n} / \mathrm{a}$ & $\mathrm{n} / \mathrm{a}$ & $50 \%$ & $7 \%$ \\
\hline Slovenia & $24 \%$ & $16 \%$ & $\mathrm{n} / \mathrm{a}$ & $\mathrm{n} / \mathrm{a}$ & $45 \%$ & $19 \%$ & $49 \%$ & $16 \%$ & $\mathrm{n} / \mathrm{a}$ & $\mathrm{n} / \mathrm{a}$ & $53 \%$ & $21 \%$ \\
\hline US & $43 \%$ & $20 \%$ & $\mathrm{n} / \mathrm{a}$ & $\mathrm{n} / \mathrm{a}$ & $40 \%$ & $22 \%$ & $35 \%$ & $14 \%$ & $\mathrm{n} / \mathrm{a}$ & $\mathrm{n} / \mathrm{a}$ & $34 \%$ & $10 \%$ \\
\hline Unwgt. Avg & $27 \%$ & $20 \%$ & $16 \%$ & $16 \%$ & $33 \%$ & $19 \%$ & $35 \%$ & $12 \%$ & $19 \%$ & $20 \%$ & $44 \%$ & $14 \%$ \\
\hline
\end{tabular}

Source: Authors calculations based on LIS data (www.lisdatacenter.org). Elderly defined as 65 years and older. Poor defined as individuals with equivalized household disposable income below $60 \%$ of national median. All data for calendar year 2010 , except Japan (2008). 